\title{
THE EYE AND AVIATION
}

\author{
WILliaM H. WILMER, M.D. (Washington, D. C.) \\ Colonel, U. S. Army \\ MINEOLA, L. I., N. Y.
}

Samuel Johnson (1759), in his "Rasselas, Prince of Abyssinia," sets forth very graphically the principles of flying. He says :

He that can swim needs not despair to fly; to swim is to fly in a grosser fluid, and to fly is to swim in a subtler. We have only to proportion our power of resistance to the different density of matter through which we are to pass. You will be upborne by the air if you can renew any impulse upon it faster than it can recede.

Professor Pike calls attention to the similarity of the labile equilibrium of the flier and of the fish. He notes the fact that in freeswimming forms, the semicircular canals are well developed; but until the otic labyrinth of the birdman has become more highly developed by change of environment, the eyes must be considered one of the most important of the peripheral sense organs concerned in the very complex problem of equilibrium. Increasing experience with the human machine in aeronautics impresses one very deeply with the feeling that from the beginning the instructions of the chief surgeon to the examining units have been very wise in insisting on good vision, sound eyes, normal muscle balance and strength, stereoscopic vision and ability to recognize colors. In the further classification of pilots, it is also very necessary to test the subjects in regard to their retinal sensitivity.

\section{GOOD SIGHT AN ESSENTIAL REQUISITE IN AVIATION}

The value of acute sight is so apparent that it seems hardly necessary to draw attention to it as an essential requisite in flying. But no other nation insists on the high standard held by the air service of the United States. It is important in distinguishing enemy planes from those of our allies, in making good landings, and in observing objects of military importance within and beyond the enemy lines. The pilot who sees the enemy first has an enormous advantage in being able to make the first maneuver. Where two planes are approaching each other at the rate of nearly 150 miles an hour (for each plane) one can readily appreciate the importance of good sight. In the tests at the laboratory we have not been able to verify the statements of French observers that the vision of the aviator at about 200 meters increases 
practically one-third owing to the congestion of the head in general and of the retina and choroid in particular.

We have found in errors of refraction, in which the focus is preserved by a muscular effort, that there is a falling off in visual acuity during oxygen want, such as one would meet in the air. This is particularly true of hyperopia, in which the accommodation weakens. It is conceivable, however, that increased visual acuity might possibly occur under three conditions:

1. In Europe, where a certain amount of myopia is allowed, there could be an increase of sight in the air owing to a relaxation of the muscle of accommodation.

2. In mild degrees of toxic amblyopia, such as is produced by tobacco, there is a certain amount of anemia of the optic nerve. In these cases, there might be during a flight an increase of visual acuity from the congestion of the intra-ocular tissues.

3 . Objects in a rarefied atmosphere are more clearly visible, and vision is improved for a while by the concentration that ensues from the sense of isolation in flying.

In point of fact, the question of change in visual acuity during oxygen deficiency has been under investigation at the laboratory for some months, yet the subjects examined have not been sufficiently numerous to make a statement on the matter authoritative. However, all records up to the present date show that vision has improved in 16.6 per cent., has become worse in 33.3 per cent., and has remained stationary in 50 per cent. The greatest care has been taken to make the tests of vision as accurate as possible by using not only the ordinary Snellen's type, but the Ives visual acuity apparatus, and the instrument devised by Lieutenant Johnson. In spite of all care, however, the elements of practice, memory, fatigue, etc., contribute largely to the possible sources of error.

\section{GOOD MUSCLE TONE NECESSARY}

Of almost as much importance as good sight is good muscle balance and strength. Otherwise there is a progressive loss of muscle tone as the pilot ascends, resulting in a restricted field of binocular fixation, double vision, and loss of accommodation. Under such conditions there would be difficulty in perceiving and placing an enemy machine and in seeing accurately the baragraph, air speed indicator, revolution counter, compass, inclinometer, drift meter and the numerous other instruments under the eye during flight.

Some time ago I examined the eyes of a pilot who had suffered from two crashes, each accident having been caused by his reading the baragraph incorrectly. The last time, he read the instrument as 
showing that he was 1,800 feet above the ground, when in fact he was only 150 feet. In this case, the difficulty was loss of accommodation owing largely to a hyperopia of 1.75 degrees.

In our practical experience, exophoria and hyperphoria are much more serious than esophoria. It has been found that in about 7.37 per cent. of subjects whose muscle strength is normal, there is a decrease in the field of fixation, while this decrease in the field of fixation occurs in 50 per cent. when the muscle strength is subnormal. In these cases, the decrease in the field is more marked in the upper than in the lateral or in the lower portions. In general, one may say that there is a progressive falling off in the muscle strength as the artificial altitude increases.

\section{OTHER VISUAL FACTORS THAT ARE IMPORTANT}

The power of stereoscopic vision is not considered necessary by enemy nations, and even allied nations do not consider it requisite because its requirement is too stringent. However, its possession is a great asset. This, added to good vision and muscle strength, aids greatly in judging distances, and therefore in making a good landing. For it is harder to make good landings than to do seemingly very difficult stunts in the air. Crashes due to faulty landings are most numerous. In landing, it has been pointed out by Dr. Anderson that the pilot misjudges his distance from the ground and either flattens out too soon and "pancakes," or flattens out too late and strikes the ground at a great angle, usually overturning and wrecking the machine. So far there is no definite falling off in the function of stereoscopic vision during reduced oxygen tension until just before a general break comes.

Good color vision is essential for the pilot in order that he may readily differentiate the markings of planes and distinguish between those of the enemy and those of friends. In landing at night, it is essential to distinguish the signal lights at the airdromes and to locate thereby his own field and hangar. So far our tests do not show any decided change in color vision during decreased oxygen tension.

On account of the very nature and design of the plane, the visual field of the airman is contracted irregularly. There is a central portion cut out below and the field is further limited by the wings and interfered with by the wires, struts, etc. However, it is of importance that the remaining field should be acute for catching the motion of an object, an oncoming plane, or landmarks in landing. The art of picking up objects with the peripheral retina, which is probably well developed in the lower animals, is increased in the airman by practice. The famous French "ace," Nungesser, says: "You need eyes all around your head, and after a time you get them." 
While our tests of the fields are not based on large enough numbers to be conclusive, in general, we have found a tendency toward enlargement of the fields for white and colors up to 5,000 feet; and from 5,000 to 15,000 feet the fields -have remained fairly constant, while at 20,000 feet there is a general constriction of the visual fields in which green suffers the most contraction.

Normal retinal sensitivity is important for aviators of all types, but it is a sine qua non for those who fly at night. Retinal sensitivity may be tested in two ways:

1. Threshold Sensitivity: By determining the least light stimulus the retina is conscious of by increasing the intensity of the stimulus until the eye is conscious of its existence. This method requires the complete adaptation of the eye by remaining in the dark for at least fifteen minutes. This requires too much time and care.

2. Contrast Sensitivity: The light being constant the subject is tested by seeing the minimum contrast that the retina is capable of recognizing. For practical purposes, the test object is a gray letter on a light gray background, there being thirteen shades of perceptible difference between them. Then one eye is closed and the photometric wedge is passed before the other eye until the letter blends into the background and can no longer be recognized. The point is noted on the millimeter scale of the wedge where this occurs. This is repeated three times for each eye. This wedge, which was devised by Lieutenant Reeves, consists of a layer of gelatin of increasing density of color between two pieces of optical glass. The light transmission has been calculated for each millimeter on the scale and the normal has been established by repeated tests at the laboratory.

\section{PROTECTION OF THE EYES}

The question of protection of the eyes of the pilot from wind and bright light is a most important one. The protective goggles should be of good optical glass, free from irregularities, and should afford high transmission. Their contour should permit the widest field of vision possible. The metal portion of the frame should be so constructed that there would be no danger of its being driven forcibly into the eye or face. Nearly all accidents to the eyes and head occur through the head being forcibly thrown against the fuselage in making a bad landing. Colorless lenses may be worn simply as a protection against the wind. However, the glare encountered in flying above clouds or over sand, snow or water is not only blinding to the vision, but is exhausting to the nervous apparatus by overstimulation of the retina. In the morning, when flying against the enemy, our pilots have to fly with the sun directly in their eyes. In flying away from 
the sun, when it is near the horizon, I personally have found that.there is a very fatiguing shimmering reflection from the rapidly moving propeller blades. Under these conditions a tinted glass gives a great sense of relief. The best tint for this purpose is a glass with a greenish yellow tint. While giving a high transmission of those spectral rays which are most useful for acute vision, this tint cuts out the harmful short rays and does not change the color of red, greens or blues. It not only protects the sensitive nervous expansion (the retina) from the irritating actinic rays, but it is restful by preventing the necessity of the muscular apparatus of the eye having to adjust the lens to the shorter wave lengths. In addition, this tint actually increases the visual acuity in dust, smoke, mist and fog, by preventing the diffraction and dispersion of light rays by the small particles that produce these atmospheric conditions. It acts as a ray filter, and helps in the detection of camouflage, especially the form produced by paint.

It seems necessary to lay a little stress on the matter of this tint because many rather vague suggestions as to the best tint have been put forward by some observers. It has even been noted that neutral tinted glasses have been suggested because they dim the entire visible spectrum. No airman, however, will wear goggles that materially diminish vision centrally or limit it laterally. An English flier tersely remarked concerning an official goggle: "These are sudden death overseas. You cannot see out of the sides."

The delicate mechanism of the eye indicates as surely as the other organs do the falling off in function during the nervous and physical fatigue of flying and fighting in an atmosphere of diminished oxygen tension, and points to the necessity of proper physical training and expert medical care to prevent the otherwise inevitable staleness of the aviator.

\section{COMMENT}

The sense of dizziness and insecurity that one feels on the top of a high building or by rushing water does not exist in the air. Beneath, the earth lies serene and like a beatiful map. The cultivated fields are like bits of brown velvet, and the trees stand out like the Noah's Ark trees of our childhood. It is true that the earth does rush toward one in a nose dive, that it drifts away in a rapid ascent, and that it playfully tilts up in banking, but one's isolation lends a feeling of stability and security. Were it possible to eliminate the whir of the motor, one would experience the feeling of a "peace that passeth understanding."

For their interest and ability in attacking the many necessary problems and in making careful tabulations of results, I desire to express my obligation to, and my appreciation of Captain Berens (the head of the Ophthalmological Department of the Medical Research Laboratory) and his able co-workers. 